\title{
А.С. Столетова
}

\section{РОЛЬ БИБЛИОТЕК В ОРГАНИЗАЦИИ КУЛЬТУРНО-ДОСУГОВОЙ СФЕРЫ НАСЕЛЕНИЯ ЕВРОПЕЙСКОГО СЕВЕРА РОССИИ В 1950-1960-е гГ. (НА ПРИМЕРЕ АРХАНГЕЛЬСКОЙ И ВОЛОГОДСКОЙ ОБЛАСТЕЙ)}

\author{
Статья подготовлена при финансовой поддержке РГНФ, проект 14-01-00341 \\ «Социальные отношения в российской деревне 1930-1980-х г2. и их интерпретация в уровнях общественного сознания».
}

\begin{abstract}
Рассматривается процесс численного роста контингента читателей массовых библиотек в 1950-1960-е гг. на примере Архангельской и Вологодской областей. Определяется число пользователей областных, городских, районных и сельских библиотек, приводятся сведения о читательской активности. Характеризуются основные категории читателей библиотечных учреждений. Делается вывод о том, что к концу 1960-х гг. основу читательской массы составляли специалисты различных отраслей народного хозяйства, науки и культуры, обслуживанию которых уделялось особое внимание. Устанавливаются причины трудностей в организации работы с населением в сельской местности, а также пути их решения. Описываются формы работы персонала библиотек с читателями, раскрывается содержательная сторона культурно-массовой деятельности.

Ключевые слова: библиотека; читатель; литература; культура; культурно-массовая работа.
\end{abstract}

В советском государстве одними из важнейших задач были привлечение читателей в библиотечные учреждения и увеличение спроса на книгу. Советская литература была призвана к содействию в воспитании трудящихся «в духе высокой идейности и преданности коммунизму», выполнению производственных планов и социалистических обязательств, укреплению трудовой дисциплины, а также должна была способствовать повышению производительности труда, культурного роста граждан, тем самым обеспечивая развертывание промышленности, строительства, подъем сельского хозяйства. Поэтому расширение сети библиотек, пополнение их фондов, разнообразие форм пропаганды книги были нацелены на усиление притока читателей. В соответствии с указаниями государственных органов в стране была развернута работа по доведению книги до каждой рабочей и колхозной семьи, до каждого грамотного [1. Оп. 10. Д. 9. Л. 97, 98; Оп. 11. Д. 22. Л. 6, 8; 2. С. 6-8]. В данной статье мы остановимся на рассмотрении деятельности городских, районных и сельских государственных массовых библиотек, подведомственных Министерству культуры РСФСР и составляющих основу библиотечной сети региона. Сеть культурно-просветительных учреждений также включала колхозные, специальные, профсоюзные, ведомственные библиотеки, однако их работу проследить сложнее ввиду происходивших процессов по реорганизации, упорядочению и объединению учреждений. Источниковая база позволяет определить численный состав указанных элементов системы и тенденции их развития, но не охарактеризовать возможности обслуживания населения, что в свою очередь является предметом для дальнейших изысканий.

Изучение читателей библиотек следует начать с рассмотрения проблемы эволюции их численного состава. Для подъема библиотечного дела, усиления ру- ководства сетью массовых библиотек, книгоизданием, книготорговлей и всеми культурно-просветительными учреждениями 15 марта 1953 г. Указом Президиума Верховного Совета СССР «Об объединении министерств и ведомств» было образовано союзнореспубликанское Министерство культуры СССР [1. Оп. 10, 11. С. $1 ; 3]$.

Указом Президиума Верховного Совета РСФСР от 1 апреля 1953 г. «Об образовании министерств РСФСР и преобразовании некоторых органов государственного управления РСФСР» было образовано Министерство культуры РСФСР [4]. В составе всех массовых библиотек большинство представляли библиотеки Министерства культуры. В 1950-1960-е гг. число читателей самостоятельных массовых библиотек Министерства культуры РСФСР возросло. К примеру, если в 1950 г. в библиотеках республики состояли 14,9 млн, то в 1965 г. - 34,6 млн человек [5. С. 490]. Тенденция была характерна и для рассматриваемого региона. Количество читателей библиотек системы Министерства культуры в Архангельской области в 1951 г. составляло 201,5 тыс., в 1960 г. - 296,2 тыс. человек. В Вологодской области в те же годы насчитывалось 298,1 и 475,6 тыс. читателей [6. Оп. 3. Д. 165. Л. 21; 7. Оп. 1. Д. 488. Л. 121; 8. Оп. 1. Д. 3297. Л. 21, 31].

Среди всех массовых библиотек региона высокие показатели интенсивности чтения, активности посещения библиотеки, степени использования фонда в рассматриваемый период наблюдались у областных, а самые низкие - у сельских библиотек [8. Оп. 1. Д. 3124. Л. 7, 8; 9. Оп. 7. Д. 29. Л. 18-19]. В областных библиотеках региона в начале 1950-х гг. состояли от 14 до 18 тыс. читателей, а во второй половине 1960-х гг. - до 18-25 тыс. В крупных городских библиотеках региона в начале 1950-х гг. были учтены 10-12 тыс. человек, в 1965-1967 гг. их число возросло до 16-20 тыс. В иных 
городских библиотеках, в том числе детских, как правило, читателями значились от 1 до 10 тыс. человек. Районные библиотеки охватывали от 1 до 3 тыс., сельские - до 1 тыс. читателей [6. Оп. 3. Д. 165. Л. 40-41; 8. Оп. 1. Д. 125. Л. 3; Оп. 1. Д. 4713. Л. 3; Оп. 1. Д. 4719. Л. 5; 10. Оп. 17. Д. 131. Л. 38; 11. Оп. 2. Д. 1139. Л. 12; 12. С. 55,65$]$. Однако в городской и сельской местностях каждый пользователь библиотеки прочитывал до 20-30 книг в год [6. Оп. 3. Д. 165. Л. 40; 11. Оп. 2. Д. 1139. Л. 12].

Основными группами читателей массовых библиотек на протяжении исследуемого периода являлись служащие, учащиеся, рабочие. Архангельскую областную библиотеку им. Н.А. Добролюбова в 1950-1960-е гг. посещали школьники, студенты, учителя, рабочие, инженеры, служащие, специалисты различных областей знаний, научные работники и моряки [8. Оп. 1. Д. 120. Л. 10; 13. С. 3; 14. С. 2]. Так, в 1953 г. было обслужено 2190 специалистов и научных работников, 2671 служащий, 10829 учащихся, 1615 рабочих [8. Оп. 1. Д. 120. Л. 10]. При проведении анализа годовых отчетов Вологодской областной библиотеки было установлено, что численно преобладающими группами читателей на протяжении исследуемого периода были служащие, учащиеся, рабочие, имеющие, как правило, среднее образование. Так, в 1952 г. библиотеку посещали 5629 служащих, 5757 учащихся, 1954 рабочих. В 1960 г. читателями областной библиотеки являлись 6104 учащихся, 5801 служащий, 4957 рабочих [8. Оп. 1. Д. 3124. Л. 9; Оп. 1. Д. 125. Л. 4].

Со второй половины 1960-х гг. сотрудниками библиотек уделялось большое внимание обслуживанию преобладающей среди других категории специалистов. В отчете Архангельской библиотеки за 1965 г. отмечалось, что обслуживание читателей велось дифференцированно, были выделены 3 группы: специалисты (всех возрастов), молодежная (студенты, учащиеся, другие 16-25-летние), общая (рабочие и служащие и другие категории, старше 25 лет). Группа рабочих составляла $18 \%$, специалистов - 24,2\% [8. Оп. 1 . Д. 4713. Л. 4, 5, 7].

В конце 1960-х гг. основное внимание коллектива библиотеки было направлено на обслуживание специалистов: врачей, учителей, инженеров, юристов [15. С. 4]. К концу 1960-х гг. специалисты народного хозяйства, науки и культуры становятся основой читательской массы Вологодской областной библиотеки, среди них динамично возрастало число инженернотехнических работников. Активно посещали библиотеку рабочие промышленных отраслей народного хозяйства, учителя и культпросветработники. Молодежь численно преобладала среди категорий читателей. В 1970 г. библиотекой были обслужены 5914 специалистов различных отраслей народного хозяйства и культуры, 3588 рабочих, 4765 учащихся [8. Оп. 1. Д. 125. Л. 4, 5; Оп. 1. Д. 3124. Л. 9, 29; 9. Оп. 7. Д. 29. Л. 18-19, 22, 28-29; Оп. 7. Д. 33. Л. 22; Оп. 10. Д. 24. Л. 9-10;
Оп. 10. Д. 45. Л. 4-6, 22, 24-25; Оп. 10. Д. 66. Л. 6, 49; Оп. 10. Д. 69. Л. 2; 16. С. 12].

Колхозники, рабочие районов и сел региона значились читателями библиотек не повсеместно, что определялось их занятостью, малой укомплектованностью фондов библиотек, уровнем организованности библиотечной сети [8. Оп. 1. Д. 3124. Л. 9; 9. Оп. 10. Д. 66. Л. 6, 49]. Между тем многие районные библиотеки интенсивно работали над вопросом привлечения читателей. Так, в районной библиотеке Пришекснинского района Вологодской области к 1950 г. насчитывалось 1136 читателей [10. Оп. 17. Д. 131. Л. 38]. В Каргопольской районной библиотеке Архангельской области к началу 1952 г. состояло 3188 читателей [17. C. 1]. В Лешуконской районной библиотеке Архангельской области к 1952 г. читателями значились 2504 человека, им выдавалось за год 68828 книг, т.е. читаемость достигала 27 книг [6. Оп. 3. Д. 165. Л. 40]. «К началу 1953 г. в читальном зале Исакогорской районной библиотеки Архангельской области собиралось много посетителей. Они читали свежие газеты, журналы, прослушивали лекции на различные темы», - отмечал корреспондент газеты «Правда Севера» С. Прихидный [18. С. 2].

По сведениям корреспондента газеты «Сталинская молодежь» М. Котова, в Белозерской районной библиотеке Вологодской области книги брали лекторы и пропагандисты, агитаторы, учащиеся школ и техникумов, рабочие, служащие и интеллигенция. Автор писал: «Не только из города приходят сюда читатели, но и из дальних сел. Токарь Белозерских судоремонтных мастерских В. Горин являлся активным читателем. Он интересовался художественной, технической, сельскохозяйственной, географической, медицинской, педагогической, политической литературой. Читатель Ухорядин получал книги по межбиблиотечному абонементу». К 1954 г. читателями библиотеки значились 2 тыс. человек [19. С. 2]. Улучшала обслуживание Коношская районная библиотека Архангельской области. В 1957 г. зарегистрировано 1417 читателей, в 1958 г. их число возросло до 2011 человек [20. Оп. 3. Д. 306. Л. 37]. Услугами Карпогорской районной библиотеки Архангельской области к 1962 г. пользовались 800 человек. За 1961 г. было сделано свыше 26 тыс. книговыдач. Читаемость составила 33 книги [21. С. 4].

Некоторые сельские библиотеки Вологодской и Архангельской областей уже на начало исследуемого периода имели значительное количество читателей. К примеру, в сельских библиотеках Пришекснинского района Вологодской области в 1950 г. числилось 3200 читателей [10. Оп. 17. Д. 131. Л. 38]. В отчете о работе культурно-просветительных учреждений Архангельской области за 1952 г. отмечены лучшие по показателям библиотеки. Например, Мошинская сельская библиотека Архангельской области в 1952 г. имела 689 читателей, которым за год было выдано 14264 книги, читаемость составляла 20 книг, обращаемость книжного 
фонда - 3,6, средняя посещаемость каждым читателем - 14 раз. Федьковская сельская библиотека Черевковского района Архангельской области привлекла 564 читателя, которым было выдано 11653 книги, один читатель прочитывал 21 книгу в год. В Григоровской сельской библиотеке Емецкого района Архангельской области читателями значились 517 человек, число книговыдач достигало 10 тыс. книг, читаемость составляла 19 книг в год [6. Оп. 3. Д. 165. Л. 40-41].

Тем не менее большинство сельских библиотек недостаточным образом решали задачу - иметь читателя в каждой колхозной семье [7. Оп. 1. Д. 488. Л. 117]. В 5 сельских библиотеках Великоустюгского района на 1 мая 1952 г. числилось 1257 читателей, из них только 322 колхозника. На территории Тимонинского сельсовета Белозерского района проживали более 130 колхозных семей, а сельской библиотекой пользовались только 54 колхозника. Абонементом Пришекснинской районной библиотеки пользовались всего 24 колхозника, Лежской районной - 12, а в Белозерской не было ни одного читателя колхозника, хотя на территории районного центра имелся колхоз. В сельской библиотеке Усть-Кубинского района Вологодской области в 1953 г. состояли 407 читателей, из них: учащихся - 220, колхозников - 101, служащих - 56, рабочих - 30. Причины тому, как объясняли представители бригады Комитета по делам культурнопросветительных учреждений при Совете Министров РСФСР В. Кессених, И. Вайсман, - невнимание библиотечных работников к вопросам организации обслуживания сельского населения книгой, недостаточное развитие сети передвижных библиотек и книгоношества [Там же. Л. 4-5; 22. С. 14-15].

В Архангельской области сложилось аналогичное положение. В Ненецком округе Архангельской области Оксинская библиотека к 1952 г. имела 470 читателей, абонементом пользовались 296 человек, из них 4 колхозника [6. Оп. 3. Д. 163. Л. 41]. По данным от 23 районных библиотек Архангельской области, в число читателей к 1952 г. было вовлечено 4577 колхозников, что составляло $10 \%$ к количеству читателей этих библиотек [Там же. Д. 165. Л. 23]. Среди 879 читателей Сольвычегодской районной библиотеки Архангельской области в 1958 г. значилось 16 читателей из колхозов [Там же. Л. 108].

Выполнение задачи увеличения читательского контингента проводилось путем организации подворного обхода колхозных домов работниками библиотек, передвижек, пунктов выдачи книг и книгоношества. Например, 86 районных и сельских библиотек Вологодской области в 1952 г. организовали 143 выдачных пункта, которые обслужили до 2 тыс. читателей. Всеми библиотеками было привлечено 800 книгонош, организовано 880 передвижек, из которых большинство направлялось в колхозы и на лесоучастки [7. Оп. 1. Д. 488. Л. 109].

В периоды проведения месячников книги количество читателей библиотек, как правило, возрастало.
К примеру, в Архангельской области с 10 июня по 10 июля 1951 г. в Вилегодском районе число читателей в районной библиотеке увеличилось на 84 , а в сельских библиотеках - на 65 человек [20. Оп. 2. Д. 1209. Л. 27]. За 9 месяцев 1958 г., в период Всероссийского общественного смотра культпросветучреждений, в библиотеки Архангельской области было записано 218655 человек против 208867 за этот же период 1957 г., в том числе 52189 рабочих, 28222 колхозника [Там же. Оп. 3. Д. 306. Л. 35].

В деятельности библиотек применялись как традиционные виды работы - читательские конференции, обзоры, выставки, так и качественно новые формы деятельности - дни специалиста, дни поэзии, дни библиографии, индивидуальные и коллективные информации. Наиболее полно данный перечень видов массовой работы применялся в деятельности областных и городских библиотек, которые с течением времени увеличивали число проводимых мероприятий. Так, если в 1952 г. Архангельская областная библиотека провела 162 книжные выставки, 7 читательских конференций, 6 литературных вечеров, то в 1960 г. было организовано 205 книжных выставок, 9 читательских конференций, 11 литературных вечеров. В Вологодской областной библиотеке в 1951 г. было оформлено 170 выставок, 6 вечеров, 110 обзоров, а в 1969 г. - их число увеличилось более чем в 2 раза $(359,9$ и 254 мероприятия соответственно) [8. ОП. 1. Д. 120. Л. 3, 33; Оп. 1. Д. 869. Л. 30; Оп. 1. Д. 3118. Л. 2, 45; Оп. 1. Д. 3124. Л. 13; 9. Оп. 7. Д. 36. Л. 19; Оп. 10. Д. 24. Л. 11; Оп. 10. Д. 66. Л. 3-4].

Сельские культурно-просветительные учреждения в проведении массовой работы с населением преимущественно использовали «громкие читки», беседы, викторины, выставки, организацию докладов и лекций, вечеров, оформление лозунгов, плакатов. Периодически проводились читательские конференции и литературные вечера [10. Оп. 17. Д. 131. Л. 59; 23. Оп. 1. Д. 238. Л. 17,$41 ; 24]$.

В содержании культурно-массовой работы особое место отводилось политическим, хозяйственным и культурным событиям жизни страны. В результате идеологического воздействия чаще всего обсуждались и предлагались к прочтению популярные, отмеченные государственной премией произведения, в том числе местных авторов. Как правило, они отражали темы героического подвига, передовой работы, колхозной жизни, коммунистической морали. Установившаяся практика находила отклик в читательской среде и мотивировала на последующее прочтение рекомендуемой литературы. Также среди читателей формировался спрос на книги о земляках, современниках, рабочих и происходивших в родных краях событиях [6. Оп. 3. Д. 165. Л. 28, 32-33]. Приведем некоторые примеры. В 1952 г. в Архангельской городской библиотеке им. М.В. Ломоносова была проведена читательская конференция по роману 
Г. Николаевой «Жатва», на ней присутствовали 60 человек. Выступали бригадиры, агрономы, механизаторы сельского хозяйства. Они сравнивали жизнь своих колхозов с колхозом, описанным в произведении [6. Оп. 3. Д. 163. Л. 9; Оп. 3. Д. 165. 32-33].

Как писал Б. Пономарев, роман Н.Н. Никитина «Северная Аврора», освещающий борьбу против американских, английских и французских оккупантов 1918-1920-х гг. на территории Архангельской губернии, в 1950-е гг. нашел у архангелогородцев «живой и горячий отклик». В областной библиотеке им. Н.А. Добролюбова, в Архангельской городской библиотеке им. М.В. Ломоносова, во всех районных были проведены конференции читателей, посвященные обсуждению произведения [6. Оп. 3. Д. 163. Л. 9; Оп. 3. Д. 165. Л. 28, 32; 25. С. 122].

Книга А. Морозова «М.В. Ломоносов», нашедшая широкий отклик у советской общественности и удостоенная Сталинской премии второй степени, также вызвала большой интерес у читателей Архангельской областной библиотеки, - сообщал заместитель директора Архангельской областной библиотеки С. Клюев в статье журнала «Библиотекарь» в 1952 г. Конференция прошла активно, выступил автор книги, участники отметили ее познавательное и воспитательное значение [26. С. 39-40]. В 1961 г. в Центральной библиотеке Череповца была проведена читательская конференция по книге Т.И. Осьминского и Н.В. Озерина «Очерки по истории края», которую посетили городская интеллигенция, студенты, краеведы. В январе 1965 г. читатели Череповецкой городской библиотеки обсудили книгу А.С. Бланка и А.В. Катаникова «Череповец». Там же была проведена конференция по книге А. Яшина «Вологодская свадьба», - сообщает Э.М. Прыгова [12. С. 59, 60].

В областных и городских библиотеках часто проводились встречи с местными писателями. В читальном зале Вологодской областной библиотеки в 1950-1960-е гг. выступали П.П. Вершигора, К.И. Коничев, А.Я. Яшин, С.В. Викулов, В.С. Железняк и др. [27. С. 32]. «Литературные вечера кипели от народа - желающих попасть не вмещал зал областной библиотеки», - вспоминал поэт А. Романов [28. С. 480].

Важное место в работе библиотек в 1950-1960-е гг. занимали вопросы улучшения индивидуального руководства чтением и дифференцированного обслуживания читателей. Возрастал интерес читателей библиотек к вопросам науки и техники [29. С. 2].

Как отмечалось в отчете о работе Вологодской областной библиотеки, в начале 1950-х гг. был установлен особый «стол» выдачи книг для производственной молодежи [9. Оп. 7. Д. 36. Л. 5]. В 1960-е гг. в Вологодской областной библиотеке появились залы технических, точных и экономических наук. Также были образованы сектор обслуживания работников сельского хозяйства, сектор музыкально-нотной литературы, детский сектор [16. С. 34, 36].
Повышение уровня работы библиотек по пропаганде технической литературы являлось отражением общесоюзных тенденций. В рассматриваемый период обращалось большое внимание на помощь библиотек рабочим массовых профессий [1. Оп. 11. Д. 22. Л. 9]. К примеру, в Череповецкой городской библиотеке организовывались выставки технических книг: «В помощь металлургу», «В помощь токарю», «В помощь плотнику и столяру» и т.д. Наглядные материалы, подготовленные библиотекой за 1953-1954 гг., посвящались пропаганде литературы по истории техники, проблемам технического прогресса, основам промышленного производства [30. С. 12, 15].

Особую направленность имели мероприятия на селе. Так, в Чебсарском районе Вологодской области в 1950 г. были проведены читательские конференции по книгам В. Вильямса «Основы земледелия» [10. Оп. 17. Д. 131. Л. 69]. Одна из конференций начала 1950-х гг., прошедшая в Березниковской районной библиотеке Архангельской области, как отмечал Ю. Кожухов, была посвящена обсуждению брошюры Героя Социалистического Труда холмогорской доярки А. Коробовой «Как я добиваюсь высоких удоев». На конференции присутствовали колхозники и агитаторы [24].

Как сообщал И. Полуянов, конференции по книгам «Как закалялась сталь», а также обсуждения произведений В.А. Кочетова «Журбины», Ф.А. Трофимова «Наша лесная сторона», Н.Е. Шундика «Быстроногий олень», М. Горького «Мать» прошли в середине 1950-х гг. в библиотеке рабочего комитета Березниковского леспромхоза Архангельской области [31. С. 12].

По сообщению начальника Архангельского Управления культуры В. Пузанова, в Коношской районной библиотеке Архангельской области в 1957 г. вечера, диспуты, читательские конференции и обсуждения книг проводились на темы: «Что ты читаешь?», «Образ лесоруба в художественной литературе», «Дадим Родине больше продуктов животноводства» и др. [20. Оп. 3. Д. 306. Л. 37].

А. Михайлов в 1958 г. писал, что во многих сельских библиотеках различных районов Архангельской области прошли обсуждения повести Н. Жернакова «Восход». Читатели, участники и свидетели создания первых колхозов единодушно отмечали, что коллективизация в повести была изображена так, как она проходила в их районе, в их селе. Читательские конференции по повести в сельских и колхозных библиотеках перерастали в большой разговор о положении дел в своем колхозе, бригаде, на ферме [32. С. 58].

По художественным произведениям во многих библиотеках районов региона устраивались так называемые «громкие читки». По сведениям С.В. Клюева, в начале 1950-х гг. в Черевковской районной библиотеке Архангельской области в созданных группах коллективного чтения книгу В. Пановой «Спутники» читали в течение восьми вечеров, А. Гончара «Знаменосцы»семь вечеров, Е. Кошевой «Повесть о сыне» - пять ве- 
черов, С. Бабаевского «Кавалер Золотой Звезды» шесть вечеров, Ю. Смолича «Они не прошли» - на дому у колхозников - пять вечеров. «Тихий Дон» М. Шолохова прочли коллективно в МТС за 23 вечера [33. С. 29]. В Пришекснинском районе Вологодской области в 1950 г. было организовано 611 читок, в том числе по популярным книгам: М. Бубеннова «Белая береза», В. Гроссмана «Народ бессмертен», И. Козлова «В Крымском подполье», Д. Медведева «Это было под Ровно», А. Первенцева «Честь смолоду», Е. Мальцева «От всего сердца» [10. Оп. 17. Д. 131. Л. 37].

Следует отметить, что в организации работы с читателем на селе на протяжении 1950-1960-х гг. имелись проблемы. Например, в стенограмме Архангельского областного совещания культпросветработников от 3 июля 1952 г. обозначено, что культпросветработа проводилась непосредственно на территории сельского клуба или избы-читальни, которые находились в сельсовете. С отдаленными бригадами, колхозниками работа не велась, что являлось серьезным недостатком в культурном обеспечении населения в начале 1950-х гг. [6. Оп. 3. Д. 163. Л. 30].

Как указано в справке о деятельности культпросветучреждений Вологодской области за 1953 г., работа изб-читален, сельских библиотек не охватывала всю молодежь, проводилась в отрыве от насущных задач колхозов и хозяйственно-политической жизни [7. Оп. 1. Д. 488. Л. 12, 133-137]. Так, в Леоновской сельской библиотеке Верховажского района в 1956 г. отсутствовали рекомендательные списки, что читать дояркам, свинаркам, пастуху, по уходу за посевами. Библиотека не принимала необходимых мер по дополнительному вовлечению в число читателей взрослых колхозников. Многие имевшиеся читатели-колхозники не брали книги по 3-4 месяца [10. Оп. 30. Д. 61. Л. 60].

Усилению развертывания массовой работы библиотек способствовали месячники распространения книги и смотры культурно-просветительных учреждений. Как правило, в периоды их организации библиотеки проводили комплексы мероприятий, в том числе совместно с комсомольскими организациями, клубами, Домами культуры, радио и прессой, отделе- ниями Союза писателей, книготоргами, театрами [11. Оп. 2. Д. 1305. Л. 1].

Резюмируя сказанное, отметим, что спецификой периода 1950-1960-х гг. стали осмысление значимости чтения и стремление библиотек к выполнению задач по широкому привлечению и удовлетворению запросов читателей. На протяжении исследуемого периода показатели проводимых форм массовой работы с читателем в регионе возрастали, все мероприятия были направлены на увеличение выдачи книг, идейное воспитание молодежи, расширение кругозора населения. Среди читателей формировался спрос на художественную литературу, на книги о войне, по истории советского государства, о «великих стройках», жизни советских школьников и труде учителей, деятельности колхозов, развитии сельскохозяйственной отрасли.

По мере усложнения производственной и учебной деятельности у пользователей библиотек вырабатывался интерес к научной и специальной литературе, в то же время и библиотеки уделяли большое внимание обслуживанию специалистов. В 1950-1960-е гг. акцентировалось внимание на роль книги в личной и общественной жизни. Поэтому деятельность библиотек, в частности, была направлена и на создание положительных и привлекательных образов читающего человека. В рассматриваемый период стали активно использоваться различные методы руководства чтением. На качество обслуживания читателей и повышение выдачи литературы эффективно повлияло введение в библиотеках региона в 1960-е гг. открытого доступа к фондам, т.е. свободного прохода к стеллажам и полкам с книгами, благодаря чему оно нашло широкое применение в стране [1. Оп. 11. Д. 22. Л. 11; 27. С. 32; 34. С. 4-5; 35. С. 2; 36. С. 3; 37. С. $4 ; 38$. С. 4].

Таким образом, библиотечные учреждения в организации культурно-досуговой сферы населения 19501960-х гг. играли значительную роль, о чем свидетельствуют факты роста числа пользователей, усиления спроса на книгу, внедрения разнообразных форм библиотечной работы с читательским контингентом.

\section{ЛИТЕРАТУРА}

1. Российский государственный архив литературы и искусства (РГАЛИ). Ф. 2329.

2. Руководящие материалы по библиотечному делу : справочник. 2-е изд. М. : Книга, 1968. 270 с.

3. Постановление Совета Министров СССР от 20 июня 1953 г. № 1565 «Об утверждении положения о министерстве культуры СССР» // СПС КонсультантПлюс. URL: http://base.consultant.ru/cons/cgi/online.cgi?req=doc;base=ESU;n=30709, свободный (дата обращения: 1.05.2016).

4. Постановление Совета Министров РСФСР от 25 апреля 1953 г. № 425 «О структуре и штатах центрального аппарата Министерства культуры РСФСР и его местных органов» // СПС КонсультантПлюс. URL: http://base.consultant.ru/cons/cgi/online.cgi?req=doc;base=ESU; n=23717, свободный (дата обращения: 1.05.2016).

5. Народное хозяйство РСФСР в 1965 г.: Статистический ежегодник / ЦСУ РСФСР. М. : Статистика, 1966.616 с.

6. Государственный архив Архангельской области (ГААО). Ф. 5790.

7. Государственный архив Вологодской области (ГАВО). Ф. 4794.

8. Государственный архив Российской Федерации (ГАРФ). Ф. А-501.

9. ГАВО. Ф. 635.

10. Вологодский областной архив новейшей политической истории (ВОАНПИ). Ф. 2522.

11. ГААО. Ф. 5859.

12. Прыгова Э.М. История публичной библиотеки города Череповца: посвящается 225-летию г. Череповца и 130 -летию Центральной городской б-ки им. В.В. Верещагина. Череповец : Полиграфист, 2002. 75 с.

13. Лиханова В. По заявкам читателей // Правда Севера. 1953. 31 мая. 
14. Курилов С. Сокровищница знаний // Правда. 1965. 19 янв.

15. Курилов С. На службе у мысли... // Правда Севера. 1968. 24 сен.

16. Воробьева Л.М. Из истории вологодской областной библиотеки им. И.В. Бабушкина // Материалы Первой областной научно-практической конференции библиотечных работников. Вологда, 1970. С. 3-12.

17. Фадеев А. Передвижные библиотеки в лесопунктах и колхозах // Правда Севера. 1952. 6 янв.

18. Прихидный С. Забота о читателях // Правда Севера. 1953. 7 янв.

19. Котов М. Читатель и нужды районной библиотеки // Сталинская молодежь. 1954. 18 ноя.

20. Отдел документов социально-политической истории Государственного архива Архангельской области (ГААО. ОДСПИ). Ф. 296.

21. Щепоткин А. Идут читатели в библиотеку // Правда Севера. 1962. 3 июля.

22. Кессених В., Вайсман И. Нужен решительный перелом // Библиотекарь. 1952. № 10. С. 14-19.

23. ГААО. Ф. 5932.

24. Кожухов Ю. В библиотеке села Семеновское // Правда Севера. 1951. 22 июня.

25. Пономарев Б.С. Литературный Архангельск: События, имена, факты, 1920-1980. Архангельск : Сев.-Зап. книжн. изд-во, 1982.190 с.

26. Клюев С. Читатели обсуждают книгу о Ломоносове // Библиотекарь. 1952. № 5. С. 39-40.

27. Культура Вологды, ХХ век: История. Лица. События. Вологда : Полиграфист, Б. г. 80 с.

28. Романов А. Народные корни литературы: из истории Вологодской писательской организации // Литературная Вологда. Вологда : Книжное наследие, 2007. С. 461-483.

29. Пелевина Р. Для вас, читатели областной библиотеки // Вологодский комсомолец. 1964. 5 мая.

30. Соболева Е. Пропаганда технической литературы в Череповецкой городской библиотеке. Вологда : Б.и., 1957.

31. Полуянов И.Д. Библиотека леспромхоза и ее читатели. Архангельск : Архангел. книжн. изд-во, 1956.19 с.

32. Михайлов А. Литературный Архангельск // Вопросы литературы. 1958. № 6. С. 51-67.

33. Клюев С.В. Черевковская районная библиотека. Архангельск : Архангел. обл. гос. изд-во, 1950. 50 с.

34. Богачев П.М. Об открытом доступе читателей к книжным фондам библиотек. Архангельск : Б.и., 1959. 27 с.

35. Гарин Н. В старейшей сельской // Красный Север. 1964. 29 дек.

36. Сергеев Н. В сельской библиотеке // Правда Севера. 1960. 22 ноя.

37. Шадхан 3. У книг - новоселье // Правда Севера. 1960. 4 марта.

38. Щепоткин А. Идут читатели в библиотеку // Правда Севера. 1962. 3 июля.

Stoletova Anna S. Vologda State Unversity (Vologda, Russia). E-mail: Stoletowa-A-S@yandex.ru

THE ROLE OF LIBRARIES IN THE ORGANIZATION OF CULTURAL AND LEISURE SPHERES OF THE POPULATION OF EUROPEAN NORTH OF RUSSIA IN 1950-1960. (ON THE EXAMPLE OF THE ARKHANGELSK AND VOLOGDA REGIONS).

Keywords: library; reader; literature; culture; cultural-public work.

One of the most important objectives stated by the public authority to cultural institutions in the 1950-1960, was attraction of readers into the libraries. Therefore, the purpose of this research is to identify the dynamics of a composition of the readers of the libraries, consideration forms of cultural-mass works, organized by libraries, as well as the determination of their mission and role in the organization of cultural and leisure sphere of life of the population of the European North of Russia (on the example of the Arkhangelsk and Vologda regions). The source of the base of the research amounted to archive (data of the Russian State Archive of Literature and Art, the State Archive of the Russian Federation, the State Archive of Arkhangelsk region, State Archives of Vologda Region) and published sources. The documents provide extensive information about the composition and categories of the users, the book fund and the intensity of the work of regional, municipal, district and rural libraries and the promotion of literature to the people, the organization of readers' conferences, the months of books and review of cultural-educational institutions. Legislative and regulatory legal acts of the authorities reflect the specific directions of the state policy in the field of library and book science. Materials of the state statistics and periodicals also were used for writing this research. The research provides data on the number and groups of readers of libraries of different levels, activities of institutions to service users. Characterized form of cultural-mass works, the specifics of its organization in urban and rural environments. Determined that the experts of various sectors of the economy, science and culture were the majority among the main groups of readers of libraries by the end of the 1960s. Attention was drawn to strengthening the work of urban libraries in the areas of development of individual guided reading and differentiated services to visitors. Established, gaps in the work of rural library institutions, related primarily to the very well organized library network and fully provided of funds. Showed the process of development of a network of mobile libraries and carry of the books aimed at increasing the readership of rural libraries. In this context, it demonstrates the value of reviews of cultural and educational institutions, and the month of the book. Revealed the content side and the subject of cultural and mass activity of library facilities. Provides the information on the formation of reader demand. On the basis of the presented data about the numerical growth of the readers, the varieties of readers' groups, the introduction of qualitatively new forms of cultural and mass work, the formation of stable interest to the life and work of the writers, in the article it concluded that the libraries played a significant role in the organization of cultural and leisure sphere of population 1950-1960.

\section{REFERENCES}

1. The Russian State Archive of Literature and Art (RGALI). Fund 2329.

2. Lesokhina, V.S. (1968) Rukovodyashchie materialy po bibliotechnomu delu [A Guidance on Librarianship]. 2nd ed. Moscow: Kniga.

3. The Council of Ministers of the Russian Federation. (1953a) Resolution № 1565 of the Council of Ministers dated June 20, 1953, "On Approval of the Decision about the Ministry of Culture”. [Online] Available from: http://base.consultant.ru/cons/cgi/online.cgi?req=doc;base=ESU;n=30709. (Accessed: 1st May 2016). (In Russian).

4. The Council of Ministers of the Russian Federation. (1953b) Resolution № 425 of the RSFSR Council of Ministers dated April 25, 1953, “On the structure of the states and the central apparatus of the RSFSR Ministry of Culture and of the local authorities". [Online] Available from: $\mathrm{http} / / /$ base.consultant.ru/cons/cgi/online.cgi?req=doc;base=ESU;n=23717. (Accessed: 1st May 2016). (In Russian).

5. Central Department of Statisitcs. (1966) Narodnoe khozyaystvo RSFSR v 1965 g.: Statisticheskiy ezhegodnik [The national economy of the USSR in 1965: Statistical Yearbook]. Moscow: Statistika.

6. The State Archives of Arkhangelsk Region (GAAO). Fund 5790.

7. The State Archives of Vologda Region (GAVO). Fund 4794.

8. The State Archives of the Russian Federation (GARF) Fund A-501.

9. The State Archives of Vologda Region (GAVO). Fund 635. 
10. Vologda Regional Archive of Contemporary Political History (VOANPI). Fund 2522.

11. The State Archives of Arkhangelsk Region (GAAO). Fund 5859.

12. Prygova, E.M. (2002) Istoriya publichnoy biblioteki goroda Cherepovtsa: posvyashchaetsya 225-letiyu g. Cherepovtsa i 130-letiyu Tsentral'noy gorodskoy b-ki im. V.V. Vereshchagina [The history of Cherepovets Public Library: Dedicated to the 225th anniversary of Cherepovets and the 130th anniversary of the Central City library]. Cherepovets: Poligrafist.

13. Likhanova, V. (1953) Po zayavkam chitateley [Upon readers's request]. Pravda Severa. 31st May.

14. Kurilov, S. (1965) Sokrovishchnitsa znaniy [Treasury of Knowledge]. Pravda. 19th January.

15. Kurilov, S. (1968) Na sluzhbe u mysli... [Serving the thought . . ]. Pravda Severa. 24th September.

16. Vorobieva, L.M. (1970) [From the history of the Vologda Regional Library]. Proc. of the First Regional Conference of Librarians. Vologda. pp. 312. (In Russian)

17. Fadeev, A. (1952) Peredvizhnye biblioteki v lesopunktakh i kolkhozakh [Mobile libraries in lumber camps and kolkhozs]. Pravda Severa. 6th January.

18. Prikhidnyy, S. (1953) Zabota o chitatelyakh [With care for readers]. Pravda Severa. 7th January.

19. Kotov, M. (1954) Chitatel' i nuzhdy rayonnoy biblioteki [The reader and the needs of the district library]. Stalinskaya molodezh'. 18th November.

20. Department of documents of the social and political history of the State of Arkhangelsk Region (GAAO ODSPI). Fund 296.

21. Shchepotkin, A. (1962) Idut chitateli v biblioteku [Readers go to the library]. Pravda Severa. 3rd July.

22. Kessenikh, V. \& Vaysman, I. (1952) Nuzhen reshitel'nyy perelom [We need a decisive turn]. Bibliotekar'. 10. pp. 14-19.

23. The State Archives of Arkhangelsk Region (GAAO). Fund 5932.

24. Kozhukhov, Yu. (1951) V biblioteke sela Semenovskoe [In the library of Semenovskoe]. Pravda Severa. 22nd June.

25. Ponomarev, B.S. (1982) Literaturnyy Arkhangel'sk: Sobytiya, imena, fakty, 1920-1980 [The Literary Arkhangelsk: Events, names, facts, 1920-1980]. Arkhangel'sk: North-West Book Publ.

26. Klyuev, S. (1952) Chitateli obsuzhdayut knigu o Lomonosove [Readers are discussing the book on Lomonosov]. Bibliotekar'. 5. pp. 39-40.

27. Kirillova, E.A. \& Zorina, K.P. (n.d.) Kul'tura Vologdy, XX vek: Istoriya. Litsa. Sobytiya [The Culture of Vologda, the 20th century: History. People. Events]. Vologda: Poligrafist.

28. Romanov, A. (2007) Narodnye korni literatury: iz istorii Vologodskoy pisatel'skoy organizatsii [The folk roots of literature: From the history of the Vologda writers' organization]. In: Literaturnaya Vologda [The Literary Vologda]. Vologda: Knizhnoe nasledie. pp. 461-483.

29. Pelevina, R. (1964) Dlya vas, chitateli oblastnoy biblioteki [For you, readers of the regional library]. Vologodskiy komsomolets. 5th May.

30. Soboleva, E. (1957) Propaganda tekhnicheskoy literatury v Cherepovetskoy gorodskoy biblioteke [Promotion of technical literature in the Cherepovets city library]. Vologda: [s.n.].

31. Poluyanov, I.D. (1956) Biblioteka lespromkhoza i ee chitateli [The library of the timber industry enterprise and its readers]. Arkhangelsk: Arkhangelsk Book Publ.

32. Mikhaylov, A. (1958) Literaturnyy Arkhangel'sk [The Literary Arkhangelsk]. Voprosy literatury. 6. pp. 51-67.

33. Klyuev, S.V. (1950) Cherevkovskaya rayonnaya biblioteka [The Cherevkovo District Library]. Arkhangelsk: Arkhangelsk Regional State Publ.

34. Bogachev, P.M. (1959) Ob otkrytom dostupe chitateley $k$ knizhnym fondam bibliotek [On the open access to the library book collections]. Arkhangelsk: [s.n.]

35. Garin, N. (1964) V stareyshey sel'skoy [The oldest rural]. Krasnyy Sever. 29th December.

36. Sergeev, N. (1960) V sel'skoy biblioteke [In the rural library]. Pravda Severa. 22nd November.

37. Shadkhan, Z. (1960) U knig - novosel'e [A housewarming for books]. Pravda Severa. 4th March.

38. Shchepotkin, A. (1962) Idut chitateli v biblioteku [Readers go to the library]. Pravda Severa. 3rd July. 